\title{
Prevalence of obstructive sleep apnea in female patients with fibromyalgia
}

\author{
Pinar Mutlu, MD, Çoşkun Zateri, MD, Ali Zöhra, MD, Özgür Özerdoğan, MD, Arzu N. Mirici, MD.
}

\begin{abstract}
الأهداف: تحديد مدى انتشار انقطاع النفس الانسدادي النومي لدى النساء النساء

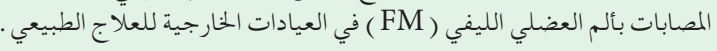

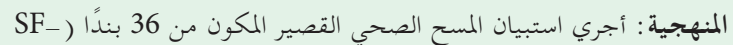

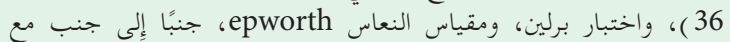

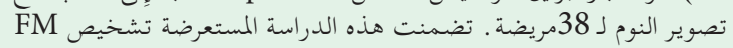

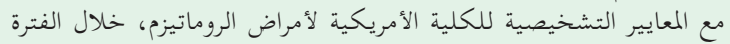

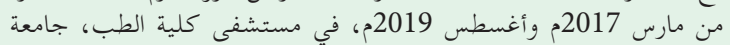
جاناكالي أونسيكيز مارت، كاناكالي، تركيا.

النتائج: وجد أن 65.9\% من المرضى يعانون من انقطاع النفس الانسدادي

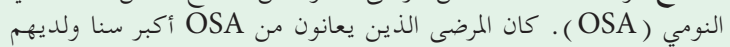

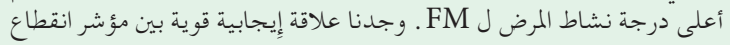

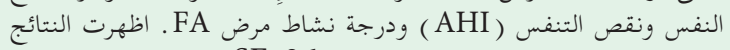

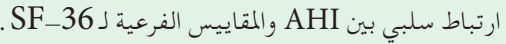

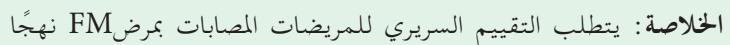

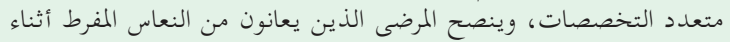

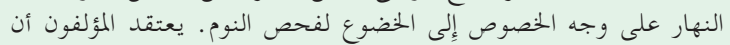

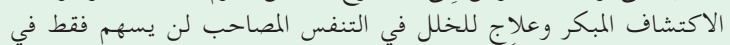

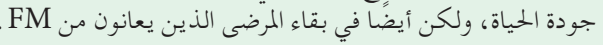

Objectives: To determine the prevalence of obstructive sleep apnea in female patients with fibromyalgia (FM) presenting to physical therapy outpatient clinics.

Methods: The 36-item short form health survey (SF-36) questionnaire, Berlin test, and epworth sleepiness scale were administered, along with a polysomnography to 38 female patients. This crosssectional study comprised diagnosed with FM according to the diagnostic criteria of the American College of Rheumatology, between March 2017 and August 2019, at the Faculty of Medicine Hospital, Çanakkale Onsekiz Mart University, Çanakkale, Turkey.

Results: Of the participants, $65.9 \%$ were found to have obstructive sleep apnea (OSA). Patients with OSA were older and had a higher disease activity score for FM. A strong positive correlation was identified between the apnea-hypopnea index (AHI) and the
FA disease activity score. A negative correlation was found between AHI and the subscales of SF-36.

Conclusion: A clinical assessment of female patients with FM requires a multidisciplinary approach, and patients with excessive daytime sleepiness in particular are recommended to undergo polysomnography. The authors believe that the early detection and treatment of accompanying OSA will contribute not only to the quality of life, but also to the survival of patients with FM.

Keywords: fibromyalgia, obstructive sleep apnea, pain, female

Saudi Med J 2020; Vol. 41 (7): 740-745

doi: 10.15537/smj.2020.7.25165

From the Department of Chest Diseases (Mutlu, Zöhra, Mirici), from the Department of Physical Therapy and Rehabilitation (Zateri), and from the Department of Public Health (Özerdoğan), Faculty of Medicine, Çanakkale Onsekiz Mart University, Çanakkale, Turkey.

Received 9th April 2020. Accepted 12th June 2020.

Address correspondence and reprint request to: Dr. Pinar Mutlu, Department of Chest Diseases, Faculty of Medicine, Çanakkale Onsekiz Mart University, Çanakkale, Turkey. E-mail: pinarmutlu78@yahoo.com

ORCID ID: orcid.org/0000-0002-7496-0026

F ibromyalgia (FM) is a syndrome with an unknown etiology that is characterized by widespread musculoskeletal pain and tenderness, fatigue, sleep disorders, excessive daytime tiredness, headaches that are more prominent in the morning, bloating and diarrhea, abdominal pain, cognitive impairment and depression. ${ }^{1}$ Due to these symptoms, patients are unable to meet the requirements of their daily lives; and their quality of life is impaired. ${ }^{2}$ Worldwide, the prevalence of FM is $0.2-6.6 \%$ and $90 \%$ of patients are women. ${ }^{3,4}$ Obstructive sleep apnea (OSA) is characterized by recurrent episodes of upper airway obstruction and 
frequent decreases in arterial oxygen saturation during sleep, and is a public health problem and it has been found to be associated with impairment in the quality of life. ${ }^{5}$ The ratio of men diagnosed with OSA to women is $8: 1$, because while the disease is monitored in men with classic OSA symptoms such as snoring, witnessed apnea and daytime sleepiness; women have weaker symptoms like morning headaches, fatigue, insomnia and feeling of exhaustion that often lead to diagnoses of both depression and FM. ${ }^{6,7}$ Do the symptoms in female patients with FM, such as fatigue, insomnia, cognitive disorders, and headache in the morning, also indicate a common pathophysiology of both diseases? Does the diagnosis of FM in female patients make us overlook the same patients in terms of OSA? Does FM in women mask OSA?

As a result of all these questions, the present study approaches female patients with FM from a new perspective in order to establish its association with OSA.

Methods. This is a cross-sectional study comprises female patients aged $\geq 18$ years, diagnosed with FM according to the diagnostic criteria of the 2011 American College of Rheumatology (ACR) in physical therapy and rehabilitation outpatient clinics between March 2017 and August 2019, who consented to participate in the study. ${ }^{8}$ Diagnosis is based on complaints of extensive pain persisting for at least 3 months and reports of pain from $4 \mathrm{kgF}$ pressure in at least 11/18 tender points on the body.

The study was approved by the Çanakkale Onsekiz Mart University Clinical Trials Ethics Committee (01.11.2017 and E.145858) and Faculty of Medicine Hospital, Çanakkale Onsekiz Mart University, Çanakkale, Turkey. The participants who gave consent for participation in the study were informed of the study objectives and methods by the researchers, and all patients provided written and verbal informed consent. The study conforms to the provisions of the Declaration of Helsinki.

The exclusion criteria were the menopausal period, either spontaneously or surgically; using benzodiazepines, agonists or sodium oxybate; presence of any kind of joint inflammatory disease or degenerative joint disease; malignancy. No sample size was selected

Disclosure. Authors have no conflict of interests, and the work was not supported or funded by any drug company. in the present study, with the goal being to reach all patients meeting the study inclusion criteria during the study period.

The study was carried out in the Faculty of Medicine Hospital, Çanakkale Onsekiz Mart University Çanakkale, Turkey. The Short Form-36 (SF-36) health survey questionnaire, Berlin test and epworth sleepiness scale were administered to the patients, and all patients underwent polysomnography (PSG). Based on the PSG results, patients with an apnea-hypopnea index (AHI) of 5-15 were considered to have mild OSA, patients with an AHI of 15-30 were considered to have moderate OSA and those with an AHI of greater than 30 points were considered to have severe OSA. Patients with an AHI of less than 5 points were considered to have no OSA. Patients with moderate and severe OSA underwent a continuous positive airway pressure (CPAP) titration study according to their clinical status and were prescribed a CPAP device.

Short form-36. The scale contains 36 items in the 8 sub-dimensions of physical functioning (10 items), social functioning (2 items), role limitations due to physical health (4 items), role limitations due to emotional problems (3 items), emotional well-being (5 items), energy/vitality ( 4 items), pain (2 items) and general health ( 5 items). The scale generates a score for each subscale rather than generating a single total score. ${ }^{9}$ Subscales are rated on a $0-100$ scale in which 0 points indicates a poor health condition and 100 points indicates a good health condition in the relevant subscale. The Turkish version of the SF-36 was validated by Koçyiğit et al. ${ }^{10}$

Berlin test. This is a questionnaire designed for the community screening of OSA, containing a total of 10 questions in 3 categories. Each category is evaluated within itself. If 2 or more categories showed a positive result, the OSA risk is considered to be high according to this questionnaire. ${ }^{11}$

Epworth sleepiness scale (ESS). This scale investigates tendency to sleep during 8 daily life activities. Each item contains 4 answers that are rated from $0-3 .{ }^{12}$ The total score in this scale is in the range of 0-24 points, with higher total scores indicating excessive daytime sleepiness. The Turkish version of the scale was validated by İzci et al. ${ }^{13}$

Polysomnography recording. All patients underwent PSG in the sleep laboratory using a 64-channel neuron-spectrum (Schreiber \& Tholen, Germany) PSG device with the American Academy of Sleep Medicine (AASM) standards, and data were scored utilizing the 2012 AASM scoring guidelines. ${ }^{14}$ 
The International Classification of Sleep Disorders, third edition, was used to adjudicate sleep disorders in our patients integrating PSG data. ${ }^{15}$ Patients with a PSG demonstrating apneas or hypopneas with an AHI $\geq 5 /$ hours were rendered a diagnosis of OSA.

Statistical analysis. The data was analyzed using the Statistical Package for Social Sciences (SPSS) version 20.0 (IBM Corp., Armonk, NY, USA). The data was expressed as number, percentage, mean, standard deviation, median and minimum-maximum values. The t-test was used according to the results of normal distribution. A Chi-square test was used for the analysis of categorical data. A correlation coefficient (r): 0-0.24 indicated a weak correlation, while an $\mathrm{r}$ : 0.25-0.49 indicated moderate, an $\mathrm{r}$ : 0.50-0.74 indicated strong, and an $\mathrm{r}$ : $0.75-1.0$ indicated a very strong correlation. A $p$-value $<0.05$ was considered significant.

Results. A total of 38 subjects were included in the study with a mean age of $52.4 \pm 8.0$ (median: 51.5 , min-max: 40-68) years. The mean AHI was $19.0 \pm 21.5$ (median: 10.6, min-max: 0.2-79.9). The ESS, SF-36 subscale scores, FM criteria, sleep duration, sleep efficiency, mean oxygen saturation measured during PSG and the lowest saturation values are presented in Table 1.

Of the participants, $36.8 \%$ were in the high-risk group according to the Berlin test; $68.4 \%$ of the study group had excessive daytime sleepiness according to the ESS; and OSA was detected in $65.9 \%$ of the participants (Table 2).

A significant relationship was noted between age, ESS, symptom impact questionnaire score (SIQR) in FM and the lowest saturation value in PSG and the presence of OSA $(p<0.05)$. The age, ESS and SIQR scores were higher in patients with OSA (Table 3).

In the comparison between AHI and other parameters, a strongly positive correlation was identified between AHI and age (r: 0.510, $p=0.001)$, a moderately positive correlation between AHI and ESS (r: $0.441, p=0.006$ ), a moderately positive correlation between AHI and the Berlin test (r: 0.453, $p=0.001$ ), a strongly positive correlation between AHI and SIQR (r: $0.619, p<0.001$ ) and a moderate negative correlation between AHI and the lowest saturation recorded during PSG (r: $-0.623, p<0.001)$. An analysis of the relationship between the AHI and SF-36 subscales showed a moderate negative correlation with the physical functioning subscale ( $\mathrm{r}$ : $-0.606, p<0.001$ ), a moderate negative correlation with the physical role limitation subscale ( $\mathrm{r}:-0.359, p=0.044)$, a strong
Table 1 - General characteristics of the study group.

\begin{tabular}{|c|c|c|}
\hline Variables & Mean \pm SD & Median (min-max) \\
\hline Age (years) & $52.4 \pm 8.0$ & $51.5(40.0-68.0)$ \\
\hline ESS & $8.9 \pm 5.6$ & $7.5(0.0-24.0)$ \\
\hline \multicolumn{3}{|l|}{ SF-36 subscales } \\
\hline $\begin{array}{l}\text { Physical functioning } \\
\text { Physical role limitation } \\
\text { Pain } \\
\text { General health } \\
\text { Energy/vitality } \\
\text { Social functioning } \\
\text { Emotional role limitation } \\
\text { Mental health }\end{array}$ & $\begin{array}{l}46.4 \pm 20.5 \\
43.0 \pm 40.8 \\
40.7 \pm 22.7 \\
46.7 \pm 17.3 \\
43.1 \pm 15.7 \\
44.5 \pm 26.4 \\
57.3 \pm 37.1 \\
49.9 \pm 16.9\end{array}$ & $\begin{array}{c}45.0(15.0-90.0) \\
25.0(0.0-100.0) \\
42.5(0.0-90.0) \\
50.0(10.0-90.0) \\
45.0(10.0-75.0) \\
43.8(12.5-100.0) \\
66.7(0.0-100.0) \\
48.0(12.0-84.0)\end{array}$ \\
\hline \multicolumn{3}{|l|}{ Fibromyalgia criteria } \\
\hline $\begin{array}{l}\text { Pain location score } \\
\text { SIQR }\end{array}$ & $\begin{array}{l}13.8 \pm 4.9 \\
25.9 \pm 12.7\end{array}$ & $\begin{array}{l}15.0(3.0-21.0) \\
24.0(0.0-46.5)\end{array}$ \\
\hline Sleep duration (minute) & $322.7 \pm 39.7$ & $325.0(222.0-394.0)$ \\
\hline Sleep efficiency & $81.2 \pm 12.2$ & $82.7(50.8-111.5)$ \\
\hline Mean saturation (\%) & $97.0 \pm 1.3$ & $97.0(94.0-99.0)$ \\
\hline Lowest saturation (\%) & $88.3 \pm 6.2$ & $90.0(72.0-97.0)$ \\
\hline Apnea-hypopnea index & $19.0 \pm 21.5$ & $10.6(0.2-79.9)$ \\
\hline
\end{tabular}

Table 2 - Sleep scores and obstructive sleep apnea (OSA) in the study group.

\begin{tabular}{lc}
\hline Variables & $\mathbf{n}(\%)$ \\
\hline Berlin test & $24(63.2)$ \\
$\quad$ Low risk $(\leq 1)$ & $14(36.8)$ \\
High risk $(\geq 2)$ & \\
Epworth sleepiness scale & $12(31.6)$ \\
Normal & $12(31.6)$ \\
Normal but increased daytime sleepiness & $4(10.4)$ \\
Increased but modest daytime sleepiness & $5(13.2)$ \\
Increased, moderate daytime sleepiness & $5(13.2)$ \\
Increased, severe daytime sleepiness & \\
OSA & $13(34.1)$ \\
Absent & $8(21.1)$ \\
Mild & $9(23.7)$ \\
Moderate & $8(21.1)$ \\
Severe &
\end{tabular}


negative correlation with the pain subscale ( $\mathrm{r}:-0.550$, $p=0.001$ ), a moderate negative correlation with the social functioning subscale ( $\mathrm{r}:-0.436, p=0.013)$ and a moderate negative correlation with the emotional role limitation subscale ( $\mathrm{r}:-0.425, p=0.015)$ (Table 4).

Discussion. Fibromyalgia progresses with widespread pain, a feeling of exhausted, anxiety, fatigue, years of restless sleep and consequently cognitive dysfunction. ${ }^{16}$ It affects the patients' quality of life by disrupting their daily lives, entertainment and sports activities, academic achievements and family lives. ${ }^{17}$ The etiopathogenesis of the disease is still uncertain and to date, no pharmacological treatment has been shown to significantly improve pain, quality of life or associated symptoms in FM patients. ${ }^{18,19}$ Also, the role of nonpharmacological treatments has not yet been clearly demonstrated due to the lack of large clinical trials. ${ }^{20}$

The mismatch in clinical and community-based studies in female/male ratios in OSA is an evidence that we cannot diagnose all OSA female patients. Late diagnosis of female patients with OSA also causes complications of the disease, more frequent exposure of female patients, and therefore reduced survival. ${ }^{21}$

Although the symptoms of FM and OSA overlap in female patients, there is a paucity of data in literature regarding the prevalence of OSA in female patients with FM, and such patients are rarely referred by the rheumatology, physical therapy, and algology outpatients to the sleep laboratory for PSG recording. In addition, the opioids and benzodiazepins that are used in pharmacotherapy of FM can further worsen OSA, and worsening OSA results in a vicious circle with the onset of increased pain perception. ${ }^{22,23}$ Hence, determining the prevalence of OSA among female patients with FM and the early institution of appropriate therapy (CPAP) may avoid unnecessary polypharmacy.

Table 4 - Correlation between the apnea-hypopnea index and other factors.

\begin{tabular}{|c|c|c|}
\hline \multirow[t]{2}{*}{ Variables } & \multicolumn{2}{|c|}{ AHI } \\
\hline & $\mathbf{r}$ & $P$-value \\
\hline Age (year) & 0.510 & 0.001 \\
\hline Epworth sleepiness scale & 0.441 & 0.006 \\
\hline Berlin test & 0.453 & $0.001^{*}$ \\
\hline \multicolumn{3}{|l|}{ SF-36 subscales } \\
\hline $\begin{array}{l}\text { Physical functioning } \\
\text { Physical role limitation } \\
\text { Pain } \\
\text { General health } \\
\text { Energy/vitality } \\
\text { Social functioning } \\
\text { Emotional role limitation } \\
\text { Mental health }\end{array}$ & $\begin{array}{r}-0.606 \\
-0.359 \\
-0.550 \\
-0.230 \\
0.072 \\
-0.436 \\
-0.425 \\
0.131\end{array}$ & $\begin{array}{r}<0.001 \\
0.044 \\
0.001 \\
0.205 \\
0.695 \\
0.013 \\
0.015 \\
0.476\end{array}$ \\
\hline \multicolumn{3}{|l|}{ Fibromyalgia criteria } \\
\hline $\begin{array}{l}\text { Pain location score } \\
\text { SIQR symptom score }\end{array}$ & $\begin{array}{l}0.321 \\
0.619\end{array}$ & $\begin{array}{r}0.069 \\
<0.001\end{array}$ \\
\hline Sleep duration (min) & -0.020 & 0.907 \\
\hline Sleep efficiency & -0.094 & 0.576 \\
\hline Mean saturation (\%) & -0.149 & 0.372 \\
\hline Lowest saturation (\%) & -0.623 & $<0.001$ \\
\hline
\end{tabular}

*Kendall rank correlation coefficient. AHI: apnea-hypopnea index, r: correlation coefficient

Table 3 - Comparison of the study group according to OSA.

\begin{tabular}{|c|c|c|c|c|c|}
\hline \multirow[t]{3}{*}{ Variables } & \multicolumn{4}{|c|}{ OSA } & \multirow[t]{3}{*}{$P$-value } \\
\hline & \multicolumn{2}{|c|}{ Absent } & \multicolumn{2}{|c|}{ Present } & \\
\hline & Mean \pm SD & Median (min-max) & Mean $\pm S D$ & Median (min-max) & \\
\hline Age (year) & $47.1 \pm 4.6$ & $46.0(40.0-57.0)$ & $55.2 \pm 8.0$ & $56.0(40.0-68.0)$ & $<0.001$ \\
\hline Epworth sleepiness scale & $5.9 \pm 3.9$ & $5.0(0.0-14.0)$ & $10.4 \pm 5.8$ & $9.0(1.0-24.0)$ & 0.007 \\
\hline \multicolumn{6}{|l|}{ Fibromyalgia criteria } \\
\hline $\begin{array}{l}\text { Pain location score } \\
\text { SIQR }\end{array}$ & $\begin{array}{l}12.2 \pm 4.4 \\
16.8 \pm 12.2\end{array}$ & $\begin{array}{l}10.5(8.0-19.0) \\
12.8(0.0-41.0)\end{array}$ & $\begin{array}{l}14.7 \pm 5.1 \\
31.1 \pm 9.9\end{array}$ & $\begin{array}{c}15.0(3.0-21.0) \\
29.0(16.0-46.5)\end{array}$ & $\begin{array}{l}0.113^{*} \\
0.001\end{array}$ \\
\hline Sleep duration (min) & $331.3 \pm 22.6$ & $331.5(284.0-373.0)$ & $318.2 \pm 46.0$ & $323.0(222.0-394.0)$ & 0.249 \\
\hline Sleep efficiency & $82.4 \pm 8.5$ & $85.5(64.2-93.8)$ & $80.5 \pm 13.9$ & $80.3(50.8-111.5)$ & 0.652 \\
\hline Mean saturation (\%) & $97.5 \pm 1.2$ & $98.0(95.0-99.0)$ & $96.8 \pm 1.3$ & $97.0(94.0-99.0)$ & 0.134 \\
\hline Lowest saturation (\%) & $92.1 \pm 3.2$ & $93.0(86.0-97.0)$ & $86.4 \pm 6.5$ & $88.0(72.0-95.0)$ & $0.001^{*}$ \\
\hline
\end{tabular}


The present study detected OSA in $65.9 \%$ of female patients with FM. In addition, $68.4 \%$ of the subjects in the study group had excessive daytime sleepiness. This prevalence rate we have determined; OSA was higher than the prevalence rates reported in the literature, both in women in the community (6-25\%) and in women with FM (4\%). ${ }^{24,25}$ Our result was closer to the $50 \%$ OSA prevalence rate determined in the study, in which both female and male FM patients were taken. ${ }^{26}$ Patients with OSA were older and had higher disease activity score for FM.

In our study, as AHI increased, hypoxemia, measured on PSG, deepened and there was a strongly negative correlation between AHI and pain. These findings are important, in that they indicate the contribution of increased tissue hypoxia on clinical deterioration in FM. Furthermore, pain scores were higher in patients with OSA, which suggests that OSA may lead to a hyperalgesic condition. It has been shown that intermittent hypoxia in OSA increases neuronal degeneration, microglia activation, HIF-1-alpha and mitochondrial reactive oxygen species, and thereby results in hyperalgesia. ${ }^{27,28}$ On the other hand, impaired sleep quality can lead to increased interleukin-6 (IL-6), interleukin-1(IL-1) and tumor necrosis factor alpha (TNF- $\alpha$ ) levels, resulting in an inflammatory response worsening FM symptoms and increased pain. ${ }^{29}$

In our study, a negative correlation was noted between AHI and the all subscales of SF-36. This suggests that the presence of OSA is associated with decreased functional capacity and worsening general well-being in female patients with FM.

Among the patients found to have OSA, 8 (21.1\%) had mild, $9(23.7 \%)$ had moderate and 8 had severe OSA. The patients with mild OSAs were advised to lose weight, to quit smoking and alcohol if such a medical history was remarkable, and to avoid using opioids and benzodiazepins for the treatment of FM. Of the 9 patients with moderate OSA, 6 underwent a CPAP titration study following PSG, along with all 8 patients with severe OSA. An appointment was made for a CPAP titration study by the sleep laboratory for 3 patients with moderate OSA. Additionally, 7 patients who used the CPAP device for at least one month were contacted by phone, and significant improvement was noted in the pain location score and SIQR symptom score after treatment when compared to the pre-treatment scores. The results of the present study are consistent with those of a study that reported a significant improvement in FM symptoms following a 3-week course of CPAP therapy in 14 patients with OSA and FM. ${ }^{30}$ Sepici et al, ${ }^{31}$ performed PSG recording in a female patient with FM who suffered from waking up tired in the morning, non-relaxing sleep, daytime sleepiness and snoring, and after diagnosing severe OSAs, they reported improvement after the initiation of CPAP therapy.

Cardiac arrhythmias are more common due to increased sympathetic activity, both in patients with FM and in those with OSA. ${ }^{30,32}$ For this reason, the association between OSA and FM should be considered important due to their effects on quality of life, but most importantly, their effects on increased mortality rates.

Study limitations. The limitations of the study include the collection of study data from a single center and the small sample size. Also, as this is a cross-sectional study, cause-effect analysis cannot be performed.

In conclusion, the present study has focused on determining the prevalence of OSA in female patients with FM with similar symptoms. Due to the high prevalence rate detected in the present study, we recommend a clinical assessment of female patients with FM using a multidisciplinary approach, and suggest that patients with excessive daytime sleepiness in particular should undergo PSG. The early detection and treatment of accompanying OSA will contribute not only to the quality of life, but also to the survival of patients with FM. Prospective studies with a larger patient population evaluating the efficacy of treatment will throw more light on this subject.

Acknowledgment. The authors gratefully acknowledge Nova Translation for English language editing. we would like to thank Çanakkale Onsekiz Mart University Scientific Research Projects Committee for supporting the project numbered 1249.

\section{References}

1. Talotta R, Bazzichi L, Di Franco M, Casale R, Batticciotto A, Gerardi MC, et al. One year in review 2017: fibromyalgia. Clin Exp Rheumatol 2017; 35: 6-12.

2. Palstam A, Mannerkorpi K. Work ability in fibromyalgia: an update in the 21st century. Curr Rheumatol Rev 2017; 13: 180-187.

3. Marques AP, Santo ASDE, Berssaneti AA, Matsutani LA, Yuan SLK. Prevalence of fibromyalgia: literature review update. Rev Bras Reumatol Engl Ed 2017; 57: 356-363.

4. National Fibromyalgia and Chronic Pain Association. What is fibromyalgia? [cited 2014]. Available from URL: https://fibroandpain.org/index.php?option=com_co ntent $\&$ view $=$ article $\&$ id $=369$ : january-february-2014newsletter\&catid $=115$ \&Itemid $=589$

5. Pinto JA, Ribeiro DK, Cavallini AF, Duarte C, Freitas GS. Comorbidities associated with obstructive sleep apnea: a retrospective study. Int Arch Otorhinolaryngol 2016; 20: 145-150. 
6. Franklin KA, Lindberg E. Obstructive sleep apnea is a common disorder in the population-a review on the epidemiology of sleep apnea. J Thorac Dis 2015; 7: 1311-1322.

7. Senaratna CV, Perret JL, Lodge CJ, Lowe AJ, Campbell BE, Matheson MC, et al. Prevalence of obstructive sleep apnea in the general population: a systematic review. Sleep Med Rev 2017; 34: 70-81.

8. Wolfe F, Clauw DJ, Fitzcharles MA, Goldenberg DL, Häuser W, Katz RS, et al. Fibromyalgia criteria and severity scales for clinical and epidemiological studies: a modification of the ACR preliminary diagnostic criteria for fibromyalgia. J Rheumatol 2011; 38: 1113-1122.

9. Carr AJ, Thompson PW, Kirwan JR. Quality of life measures. Br J Rheumatol 1996; 35: 275-281.

10. Koçyiğit H, Aydemir Ö, Fisek G, Ölmez N, Memiş A. Reliability and validity of the Turkish version of short-form-36 (SF-36). İlaç ve Tedavi Dergisi 1999; 12: 102-106.

11. Abrishami A, Khajehdehi A, Chung F. A systematic review of screening questionnaires for obstructive sleep apnea. Can J Anaesth 2010; 57: 423-438.

12. Johns MW. A new method for measuring daytime sleepiness: the epworth sleepiness scale. Sleep 1991; 14: 540-545.

13. Izci B, Ardic S, Firat H, Sahin A, Altinors M, Karacan I. Reliability and validity studies of the Turkish version of the epworth sleepiness scale. Sleep Breath 2008; 12: 161-168.

14. Berry RB, Gamaldo CE, Harding SM, Brooks R, Lloyd RM, Vaughn BV, et al. AASM scoring manual version 2.2 updates: new chapters for scoring infant sleep staging and home sleep apnea testing. J Clin Sleep Med 2015; 11: 1253-1254.

15. American Academy of Sleep Medicine. ICSD-3: The International Classification of Sleep Disorders. Darien (IL): American Academy of Sleep Medicine; 2014.

16. Borchers AT, Gershwin ME. Fibromyalgia: a critical and comprehensive review. Clin Rev Allergy Immunol 2015; 49: 100-151.

17. Clauw DJ, D'Arcy Y, Gebke K, Semel D, Pauer L, Jones KD. Normalizing fibromyalgia as a chronic illness. Postgrad Med 2018; 130: 9-18.

18. Pilar Martínez M, Miró E, Sánchez AI, Lami MJ, Prados G, Ávila D. Spanish version of the pain vigilance and awareness questionnaire: psychometric properties in a sample of women with fibromyalgia. Span J Psychol 2015; 17: E105.

19. Calandre EP, Rico-Villademoros F, Slim M. An update on pharmacotherapy for the treatment of fibromyalgia. Expert Opin Pharmacother 2015; 16: 1347-1368.
20. Prabhakar A, Kaiser JM, Novitch MB, Cornett EM, Urman $\mathrm{RD}$, Kaye AD. The role of complementary and alternative medicine treatments in fibromyalgia: a comprehensive review. Curr Rheumatol Rep 2019; 21: 14.

21. Clauw DJ. Fibromyalgia: a clinical review. JAMA 2014; 311: 1547-1555.

22. Cunningham JL, Evans MM, King SM, Gehin JM, Loukianova LL. Opioid tapering in fibromyalgia patients: experience from an interdisciplinary pain rehabilitation program. Pain Med 2016; 17: 1676-1685.

23. Aytekin E, Demir SE, Komut EA, Okur SC, Burnaz O, Caglar NS, et al. Chronic widespread musculoskeletal pain in patients with obstructive sleep apnea syndrome and the relationship between sleep disorder and pain level, quality of life, and disability. J Phys Ther Sci 2015; 27: 2951-2954.

24. Heinzer R, Vat S, Marques-Vidal P, Marti-Soler H, Andries D, Tobback N, et al. Prevalence of sleep-disordered breathing in the general population: the hypnolaus study. Lancet Respir Med 2015; 3: 310-318.

25. Gold AR, Dipalo F, Gold MS, Broderick J. Inspiratory airflow dynamics during sleep in women with fibromyalgia. Sleep 2004; 27: 459-466.

26. Köseoğlu Hİ, İnanır A, Kanbay A, Okan S, Demir O, Çeçen O, et al. Is there a link between obstructive sleep apnea syndrome and fibromyalgia syndrome? Turk Thorac J 2017; 18: 40-46.

27. Yang Z, Zhao TZ, Zou YJ, Zhang JH, Feng H. Hypoxia Induces autophagic cell death through hypoxia-inducible factor $1 \alpha$ in microglia. PLoS One 2014; 9: e96509.

28. Wu J, Li P, Wu X, Chen W. Chronic intermittent hypoxia decreases pain sensitivity and increases the expression of HIF $1 \alpha$ and opioid receptors in experimental rats. Sleep Breath 2015; 19: 561-568.

29. Roizenblatt S, Neto NS, Tufik S. Sleep disorders and fibromyalgia. Curr Pain Headache Rep 2011; 15: 347-357.

30. Chervin RD, Teodorescu M, Kushwaha R, Deline AM, Brucksch CB, Ribbens-Grimm C, et al. Objective measures of disordered sleep in fibromyalgia. J Rheumatol 2009; 36: 2009-2016.

31. Sepici V, Tosun A, Köktürk O. Obstructive sleep apnea syndrome as an uncommon cause of fibromyalgia: a case report. Rheumatol Int 2007; 28: 69-71.

32. Coy TV, Dimsdale JE, Ancoli-Israel S, Clausen J. Sleep apnoea and sympathetic nervous system activity: a review. J Sleep Res 1996; 5: 42-50. 